\title{
Estimating nearshore bedform amplitudes with altimeters
}

E. L. Gallagher ${ }^{1}$, Steve Elgar ${ }^{2}$, R. T. Guza ${ }^{3}$, E. B. Thornton ${ }^{4}$

Short title: ESTIMATING NEARSHORE BEDFORM AMPLITUDES

\footnotetext{
${ }^{1}$ Department of Biology, Franklin and Marshall College, Lancaster, PA, 17604-3003. Phone:717-291-4055, fax:717-358-4548, e-mail:edith.gallagher@fandm.edu

${ }^{2}$ Woods Hole Oceanographic Institution, MS\#11, Woods Hole, MA, 02543. Phone:508-2893614, fax:240-248-4449, e-mail:elgar@whoi.edu

${ }^{3}$ Scripps Institution of Oceanography, University of California, La Jolla, CA 92093-0209. Phone:858-534-0585, fax:858-534-0300, e-mail:rguza@ucsd.edu

${ }^{4}$ Department of Oceanography, Naval Postgraduate School, Monterey, CA 93943. Phone:830-656-2847, fax:831-656-2712, e-mail:thornton@oc.nps.navy.mil
} 
Abstract. Estimates of the heights of large (0.1-0.4 m heights and 1-10 m horizontal lengths) migrating bedforms on a sandy beach made with fixed, single-point altimeters are similar to heights estimated from profiles across the bedforms made with altimeters mounted on an amphibious vehicle that traversed the surf zone. Unlike many profiling systems, the robust, fixed altimeters can measure bedforms in bubbly, sediment-laden surfzone waters nearly continuously, including during storms, thus allowing investigation of the relationships between bedform heights and near-bottom velocities to be extended to a wide range of wave conditions. The fixed-altimeter observations of migrating bedforms suggest a sandy surfzone seafloor is not always smooth during energetic conditions with strong mean currents and large wave-orbital velocities.

Keywords: nearshore, bed roughness, megaripples, sonar altimeters 


\section{Introduction}

Bedforms are ubiquitous on sandy seafloors in shallow water (Allen 1968, Clifton et al. 1971, Dalrymple et al. 1978, Moore et al. 1984, Sherman \& Greenwood 1989, Gallagher et al. 1998, Traykovski et al. 1999, and many others). The spatial scales of commonly observed wave-driven ripples (heights of order $0.01-0.10 \mathrm{~m}$ and lengths of order 0.05-0.50 m) in the nearshore can be predicted from sediment characteristics and statistics of the near-bottom flow field (Nielson 1992, Fredsoe \& Diegaard 1992). Based on observations and predictions of wave-driven ripples, models for wave dissipation, current generation, and sediment transport usually assume that the seafloor becomes smooth (without bedforms) for high energy conditions. Larger-scale bedforms (megaripples with heights of order 0.1-0.5 m and horizontal lengths of order 1-10 m) also affect the hydraulic roughness of the seafloor. However, relationships between the spatial scales of surfzone megaripples and near-bottom velocities are not known, and often it is assumed that these large bedforms also disappear for high energy conditions. Despite their importance to sediment transport via suspension by ripple-induced turbulence (Nielson 1992, Fredsoe \& Diegaard 1992) and migration (Gallagher et al. 1998), and to bottom roughness and the corresponding hydraulic drag on near-bottom flows (Grant \& Madsen 1979, Garcez-Faria et al. 1998, Barrantes \& Madsen 2000), there are few observations of bedforms in the surf zone during storms, partially because of the difficulty of making measurements in bubbly, sediment-laden water under breaking waves.

Surfzone bedforms have been studied with diver observations (Clifton et al. 1971), with fixed (Hay \& Wilson 1994) and moving (Thornton et al. 1998) side-scan sonars, and 
with fixed (Gallagher et al. 1996, 1998) and moving (Garcez-Faria et al. 1998, Gallagher et al. 2003) sonar altimeters. Of these techniques, only the fixed altimeters work well during energetic conditions, when concentrations of bubbles and suspended sediment are highest. Here, the heights of large migrating bedforms estimated with single-point sonar altimeters mounted on fixed frames are shown to be similar to the heights estimated from spatial profiles measured with altimeters mounted on an amphibious vehicle that traversed the surf zone near the fixed frames. The amphibious vehicle measurements were limited to relatively low energy conditions with wave heights less than $2 \mathrm{~m}$. The single-point altimeters data are used to extend investigations of relationships between bedforms and near-bottom velocities to energetic conditions that include 3-m high waves and strong currents.

\section{Observations}

Bedform heights were estimated by single-point 1-MHz sonar altimeters mounted on fixed frames deployed between the shoreline and 5-m water depth, along about $200 \mathrm{~m}$ of the coast near Duck, NC for 125 days in summer and fall 1997 (Elgar et al. 2001). The raw altimeter returns (sampled at $2 \mathrm{~Hz}$ ) were processed using a rigorously tested bottom-finding algorithm (Gallagher et al. 1996) that removes spurious acoustic returns from the water column, resulting in a time series of bottom location that is not corrupted by bubbles or suspended sediment. In addition, these time series were inspected visually to remove bad data that may have passed through the quality-control algorithms. The resulting time series of seafloor location (one value every $64 \mathrm{~s}$ ) were linearly detrended over 45 hours to remove large-scale erosion or accretion, and the root-mean-square (rms) fluctuation of the bottom 
elevation $\sigma_{z}$ was assigned at the center of the 45 -hr period. The 45 -hr detrending window was then slid $3 \mathrm{hrs}$ ahead, and the next $\sigma_{z}$ value estimated.

Window length is a compromise between stationarity and sufficient time for several megaripples (wavelength about $3 \mathrm{~m}$ ) to pass beneath the altimeter [propagation speeds are 0.3 to $1.2 \mathrm{~m} / \mathrm{hr}$ (Gallagher et al. 1998, Ngusaru \& Hay 2004)]. Changes in bedform type (ie, lack of stationarity) can be caused by abrupt (few hours) transitions between low- and high-energy conditions. Although tidally induced variations in bedforms could occur during the 45-hr window period, the heights of megaripples observed at Duck are not strongly tidally modulated (Ngusaru \& Hay 2004). In addition, estimates of $\sigma_{z}$ can be corrupted by rapid ( $<45 \mathrm{hr}$ ) large-scale morphological change, such as caused by sandbar migration during storms, that is not completely removed by the linear detrending of the time series over the 45-hr window. Time series of seafloor location were inspected visually, and $\sigma_{z}$ values contaminated by large-scale bed change or bedform nonstationarity were rejected. Although the results are not affected greatly by using shorter (eg, $21 \mathrm{hrs}$ ) processing periods, $45 \mathrm{hrs}$ produced the best results for the comparisons discussed here.

On 22 days during Oct 1997, a 5-m wide array of 7 altimeters mounted on an amphibious vehicle surveyed a $500 \mathrm{~m}$ cross-shore by $700 \mathrm{~m}$ alongshore area of the nearshore (which included the fixed sensor array) by traversing from the shoreline to about 5-m water depth along 20 cross-shore lines separated by 20 to $50 \mathrm{~m}$ in the alongshore (Gallagher et al. 2003). Estimated distances to the seafloor from the 7 altimeters were corrected for vehicle motion, producing spatial maps of the seafloor location along each traverse. The root-mean-square bed level fluctuation $\sigma_{z}$ was calculated by integrating from 0.1 to $10 \mathrm{~m}$ wavenumber spectra 
(averaged over the 7 altimeters) of 10-m long sections of each traverse (see Gallagher et al. 2003 for details).

\section{Results}

The estimation of $\sigma_{z}$ at a single, fixed location assumes that bedforms migrate with constant form under the altimeter (Gallagher et al. 1998, Ngusaru \& Hay 2004) so that temporal variability of the seafloor location approximates spatial variability. For example, when the seafloor at the outer edge of the surf zone (water depth approximately $1.8 \mathrm{~m}$, significant wave height $0.6-0.7 \mathrm{~m}$ ) contained 0.2 -m high bedforms, spatial observations made with the mobile altimeters (Figure 1a) have about the same $\sigma_{z}(\approx 0.041 \mathrm{~m})$ as $\sigma_{z}(\approx 0.039$ m) estimated from a 45-hr long time series of seafloor fluctuations. The time series are centered on the time of the spatial observations, and are located near the center of the spatial observations (Figure 1b). Bedform heights are approximately Rayleigh distributed (Thornton et al. 1998), and thus are about $4 \sigma_{z}$.

The corresponding cross-shore distribution of $\sigma_{z}$ estimated by the fixed, single-point altimeters is similar to that estimated with the altimeters that traversed the surf zone (Figure 2a, 2c). Nearshore bedforms occur in patches of $\mathrm{O}(10-50 \mathrm{~m})$ (Gallagher et al. 2003), and the fixed, single-point altimeters cannot resolve spatial fluctuations in $\sigma_{z}$ on scales smaller than the sensor separation. However, even with large cross-shore variation of $\sigma_{z}$, the two types of estimates are similar (Figure 2d).

Over a 22-day period, estimates of $\sigma_{z}$ made with the fixed altimeters are similar to those made with the mobile altimeters (correlation $=0.6$, Figure 3 ), suggesting that bedforms 
often migrated sufficiently rapidly for sampling with the fixed altimeters. However, there is considerable scatter, and the best fit line in Figure 3 has a slope of about $0.6 \pm 0.1$, indicating $\sigma_{z}$ estimates from the fixed altimeters are lower than $\sigma_{z}$ from the mobile altimeters. The cross-shore transects sampled with the mobile altimeters were within $20 \mathrm{~m}$ of the frames holding the fixed altimeters, but significant alongshore inhomogeneity [ie, patchiness observed by Gallagher et al. (2003) and with the fixed altimeters (not shown)] of $\sigma_{z}$ may cause some of the scatter in Figure 3. In addition, some scatter may be caused by changing conditions over the 45-hr averaging period of the fixed altimeters. Using 21-hr periods to estimate $\sigma_{z}$ results in closer correspondence between the two methods when bedforms are migrating rapidly enough for several to pass beneath an altimeter. However, for some conditions 21 hours is too short and $\sigma_{z}$ is underestimated, because if only one or two megaripple cycles are sampled, the linear detrending can reduce $\sigma_{z}$ artificially.

The average (over time) cross-shore distribution of $\sigma_{z}$ estimated with fixed, single-point altimeters is similar to that estimated with the mobile altimeters (Figure 4). The single-point altimeter observations extend observations of the cross-shore distribution of $\sigma_{z}$ from the 22 mobile altimeter surveys with offshore significant wave height less than $2 \mathrm{~m}$ to nearly continuous observations over 125 days that included several storms with wave heights greater than $3 \mathrm{~m}$. The cross-shore distribution of $\sigma_{z}$ averaged over 125 days (not shown) is similar to the $\sigma_{z}$ from 22 days (Figure 4).

The relationship between bedform heights and near-bottom fluid velocities often is parameterized by the ratio of fluid forcing to the gravitational resistance to motion of the 
sediment, given by the mobility number

$$
M=\frac{<U^{2}+V^{2}>}{(s-1) g D},
$$

where $U$ and $V$ are the temporally averaged $(<>)$ total near-bottom cross- and alongshore velocities, $s$ is the specific gravity of the sediment ( $s=2.65$ for quartz sand), $g$ is gravitational acceleration, and $D$, the grain diameter, was estimated with surface samples obtained near the fixed altimeters once in Sep and once in Oct 1997. Root-mean-square and mean velocities used to estimate $M$ were averaged first over the 3 -hr records and then over the $45-\mathrm{hr}$ window used for $\sigma_{z}$. The near-bottom velocities were measured with bidirectional electromagnetic current meters mounted approximately $0.5 \mathrm{~m}$ above the seafloor and about $0.5 \mathrm{~m}$ alongshore of each altimeter.

Although there is considerable scatter, the maximum bedform heights occurred with moderate values of the mobility number $(10<M<120$ in Figure 5), consistent with previous studies of subaqueous (including rivers) bedforms (Fredsoe and Deigaard 1992, Middleton and Southard 1984). Using the Sheilds' parameter instead of $M$ gives similar results (Gallagher et al. 2003, not shown). However, the mechanisms for the formation of bedforms in the nearshore are not understood, and existing models for wave-orbital ripple height given near-bottom velocities and sediment characteristics (Dingler \& Inman 1976, Nielson 1981, 1992, Fredsoe \& Deigaard 1992, Soulsby 1997, Li \& Amos 1999, and many others) have poor skill predicting megaripple heights in the surf zone (Gallagher et al. 2003). Similarly, no relationship was found here between megaripple heights estimated with the single-point altimeters and published formulas for heights of wave-orbital ripples (similar to 
Gallagher et al. 2003, not shown here).

Many studies suggest there is a transition to sheet flow and therefore a smooth bed at high mobility number $M$ [eg, $M=156$ (Nielson 1992), $M=240$ (Dingler \& Inman 1976), dotted lines in Figure 5], consistent with surfzone observations limited to offshore wave heights less than about $2 \mathrm{~m}$ (Gallagher et al. 2003). Although migrating megaripples sometimes were absent for high Mobility numbers (eg, $\sigma_{z} \approx 1.0 \mathrm{~cm}, M \approx 275$, Figure 5 ), the observations with the fixed altimeters also show that large bedforms can exist under energetic waves with strong near-bottom velocities $\left(\sigma_{z}>3 \mathrm{~cm}\right.$, corresponding to bedform heights $>12 \mathrm{~cm}$, for $M$ as high as 300 in Figure 5). The large variability in $\sigma_{z}$ for fixed Mobility or Sheild's numbers (eg, $1.0<\sigma_{z}<6.5 \mathrm{~cm}$ for $M \approx 275$ in Figure 5) is not understood. Although the 3-hr $M$

values sometimes fluctuated significantly during the 45-hr window used to estimate $\sigma_{z}$, several of the observations of large bedforms and high $M$ occurred during periods with relatively stable $M$. For example, for the data points in Figure 5 with $M \approx 275$ and $\sigma_{z} \approx 6.5 \mathrm{~cm}$, the standard deviation of $M$ within the 45-hr averaging period was only about 50 .

\section{Conclusions}

The heights of nearshore megaripples on a sandy beach estimated with altimeters mounted on fixed frames are similar to bedform heights estimated from spatial surveys of the seafloor obtained with altimeters mounted on an amphibious vehicle that traversed the nearshore. Although the mobile altimeters provide spatially dense estimates of bedform morphology, the surveys are limited by wave conditions, hours of daylight, and the time required to complete a survey (eg, only one survey per day was possible). In contrast, fixed, 
single-point altimeters operate nearly continuously, including in the surf zone during storms, and thus can be used to estimate bedform heights in a wide range of conditions. However, fixed altimeter estimates of bedform height are degraded if bedforms move too slowly for at least a few megaripples to propagate past the instrument during each estimation period. Furthermore, changes in bedform height during each estimation period are not resolved.

During a 125-day observational period with several storms (offshore significant wave heights about $3 \mathrm{~m}$ ) separated by calm periods (wave heights as small as $0.2 \mathrm{~m}$ ), average bedform heights decreased from about $16 \mathrm{~cm}$ near the shoreline (approximately 1-m water depth) to about $4 \mathrm{~cm} 400 \mathrm{~m}$ farther offshore in 5-m water depth. Consistent with existing models and observations, bedforms were largest for moderate mobility numbers. In contrast to the models, large bedforms (heights $>15 \mathrm{~cm}$ ) were sometimes present during storm conditions with large mobility numbers.

Acknowledgments. The fixed instrument array was deployed and maintained by staff from the Center for Coastal Studies, Scripps Institution of Oceanography. The mobile altimeter array was designed and operated by staff from the Naval Postgraduate School, and mounted on an amphibious vehicle operated by staff from U.S. Army Corps of Engineers Field Research Facility, who also provided excellent logistical support for the entire field experiment. T.H.C. Herbers, B. Raubenheimer, and T.P. Stanton helped design the arrays, participated in collection and processing of the data, and made valuable comments. Funding was provided by the Office of Naval Research, the Army Research Office, the National Research Council, and the National Science Foundation. 


\section{References}

Allen, J. R. L., 1968. Current ripples; their relation to patterns of water and sediment motion. North-Holland Pub. Co., Amsterdam.

Barrantes, A. I., and O. S. Madsen, 2000. Near-bottom flow and flow resistance for currents obliquely incident to two-dimensional roughness elements. J. Geophys. Res. 105, 26,253-26,264.

Clifton, H. E., R. E. Hunter, and R. L. Phillips, 1971. Depositional structures and processes in the non-barred high-energy nearshore. J. Sed. Petrol. 41, 651-670.

Dalrymple R. W., R. J. Knight, and J. J. Lambiase, 1978. Bedforms and their hydraulic stability relationships in a tidal environment, Bay of Fundy, Canada. Nature 275, 100-104.

Dingler, J. R., and D. L. Inman, 1976. Wave formed ripples in nearshore sands. Proc. $15^{\text {th }}$ Coastal Eng. Conf. ASCE, New York, 2109-2126.

Elgar, S., R. T. Guza, W. C. O'Reilly, B. Raubenheimer, and T. H. C. Herbers, 2001. Observations of wave energy and direction near a pier. J. Waterway, Port, Coastal, and Ocean Engr. 127, 2-6.

Fredsoe J., and R. Deigaard, 1992. Mechanics of Coastal Sediment Transport. World Sci., River Edge, N. J.

Gallagher, E. L., W. Boyd, S. Elgar, R. T. Guza, and B. Woodward, 1996. Performance of a sonar altimeter in the nearshore. Marine Geology 133, 241-248.

Gallagher, E. L., S. Elgar, and E. B. Thornton, 1998. Megaripple migration in a natural surf zone. Nature 394, 165-168.

Gallagher, E. L., E. B. Thornton, and T. P. Stanton, 2003. Sand bed roughness in the nearshore. J. Geophys. Res. 108, 3039.

Garcez-Faria, A. F., E. B. Thornton, T. P. Stanton, C. M. Soares, and T. C. Lippmann, 1998. Vertical profiles of longshore currents and related bed shear stress and bottom roughness. J. Geophys. Res. 103, 3217-3232.

Grant, W. D., and O. S. Madsen, 1979. Combined wave and current interaction with a rough bottom. J. Geophys. Res. 84, 1797-1808.

Hay, A. E., and D. J. Wilson, 1994. Rotary sidescan images of nearshore bedform evolution during a storm. Marine Geology 119, 57-65.

Jago, C., and J. Hardisty, 1984. Sedimentology and morphodynamics of a macrotidal beach, Pendine Sands, SW Wales. Marine Geology 60, 123-153. 
Li, M. Z., and C. L. Amos, 1999. Sheet flow and large ripples under combined waves and currents: field observations, model prediction and effects on boundary layer dynamics. Continental Shelf Res. 19, 637-663.

Middleton, G. V. and J. B. Southard, 1984. Mechanics of Sediment Transport. SEPM Short Course number 3, SEPM, Tulsa, OK.

Moore, J. N., W. J. Fritz, and R. S. Futch, 1984. Occurrence of megaripples in a ridge and runnel system, Sapelo Island, Georgia: morphology and processes. J. Sed. Petrol. 54, 615-625.

Ngusaru, A. S. and A. E. Hay, 2004. Cross-shore migration of lunate megaripples during Duck94. J. Geophys. Res. 109, C02006, doi:10.1029/2002JC001532.

Nielson, P., 1981. Dynamics and geometry of wave-generated ripples. J. Geophys. Res. 86, 6467-6472.

Nielson, P., 1992. Coastal Bottom Boundary Layers and Sediment Transport. World Sci., River Edge, NJ.

Sherman, D. J., and B. Greenwood, 1989. Hummocky cross-stratification and post-vortex ripples: length scales and hydraulic analysis. Sedimentology 36, 981-986.

Soulsby, R. L., 1997. Dynamics of Marine Sands. Thomas Telford Publications, London.

Thornton, E. B., J. L. Swayne, and J. R. Dingler, 1998. Small-scale morphology across the surf zone. Marine Geology 145, 173-196.

Traykovski, P., A. E. Hay, J. D. Irish, and J. F. Lynch, 1999. Geometry, migration, and evolution of wave orbital ripples at LEO-15. J. Geophys. Res. 104, 1505-1524.

Received

July 17, 2004

Figure 1.

Figure 2.

Figure 3.

Figure 4.

Figure 5. 



Figure 1. (a) Depth of the seafloor (relative to mean sealevel) observed with altimeters mounted on an amphibious vehicle versus cross-shore location. (b) Depth of the seafloor observed with an altimeter mounted on a fixed frame versus time. The spatial observations in panel (a) were obtained approximately $1200 \mathrm{hrs}$, Oct 08, 1997, the center of the time series shown in panel (b). The temporal observations in panel (b) were obtained at cross-shore location $x=185 \mathrm{~m}$, near the center of the spatial series shown in panel (a). The measurements were separated approximately $15 \mathrm{~m}$ in the alongshore. The spatial observations show the presence of $0.2 \mathrm{~m}$ high bedforms, which also appear in the time series because they migrate beneath the fixed altimeter. 

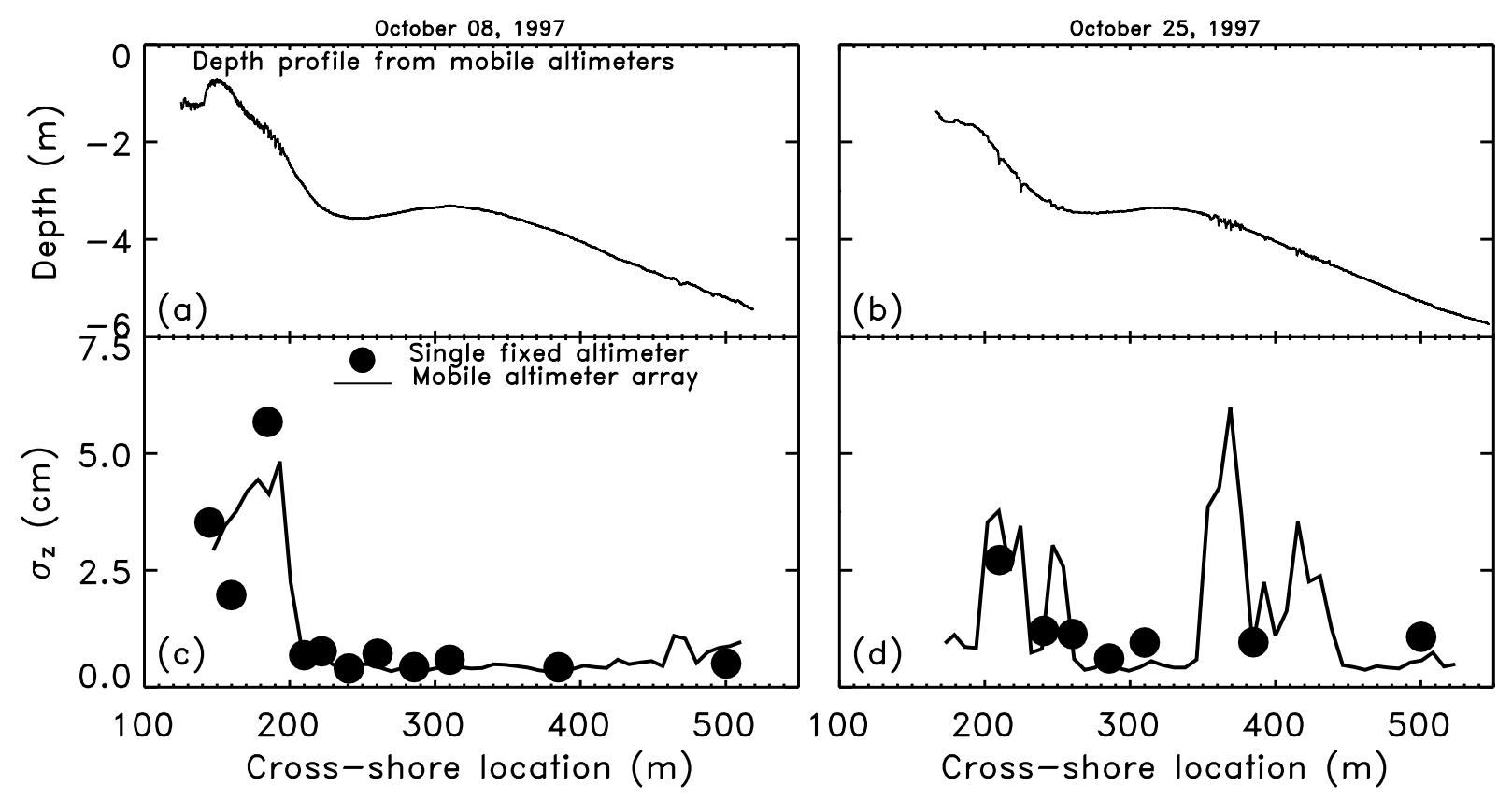

Figure 2. Depth of the seafloor (relative to mean sealevel) versus cross-shore location estimated from altimeters mounted on an amphibious vehicle on (a) Oct 08 and (b) Oct 25. Large bedforms occur for $x \leq 200 \mathrm{~m}$ in (a), and near $360 \leq x \leq 420 \mathrm{~m}$ in (b). Corresponding rms bedform amplitude $\sigma_{z}$ estimated by the mobile altimeters (curves) and by fixed, single-point altimeters (symbols) versus cross-shore location are shown in panels (c) and (d). 


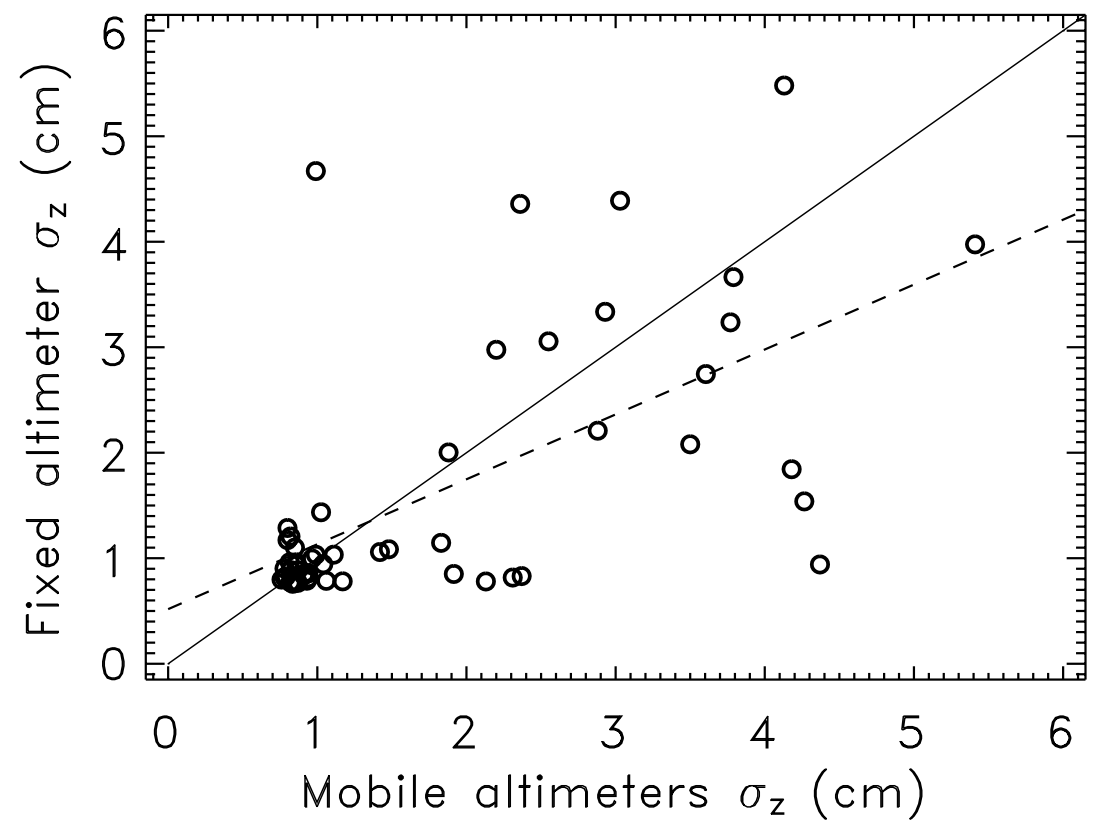

Figure 3. Root-mean-square bedform amplitude $\sigma_{z}$ estimated with fixed, single-point altimeters versus $\sigma_{z}$ estimated with the mobile altimeters. The solid line is one-to-one correspondence, and the dashed line is a least squares fit (correlation $=0.6$, slope $=0.6 \pm 0.1(95 \%), 53$ observations). Including $\sigma_{z}$ estimates less than $0.75 \mathrm{~cm}$, corresponding to bedform heights less than about $3 \mathrm{~cm}$, increases both the correlation and slope to 0.7 , but are excluded here to emphasize larger-scale bedforms. 


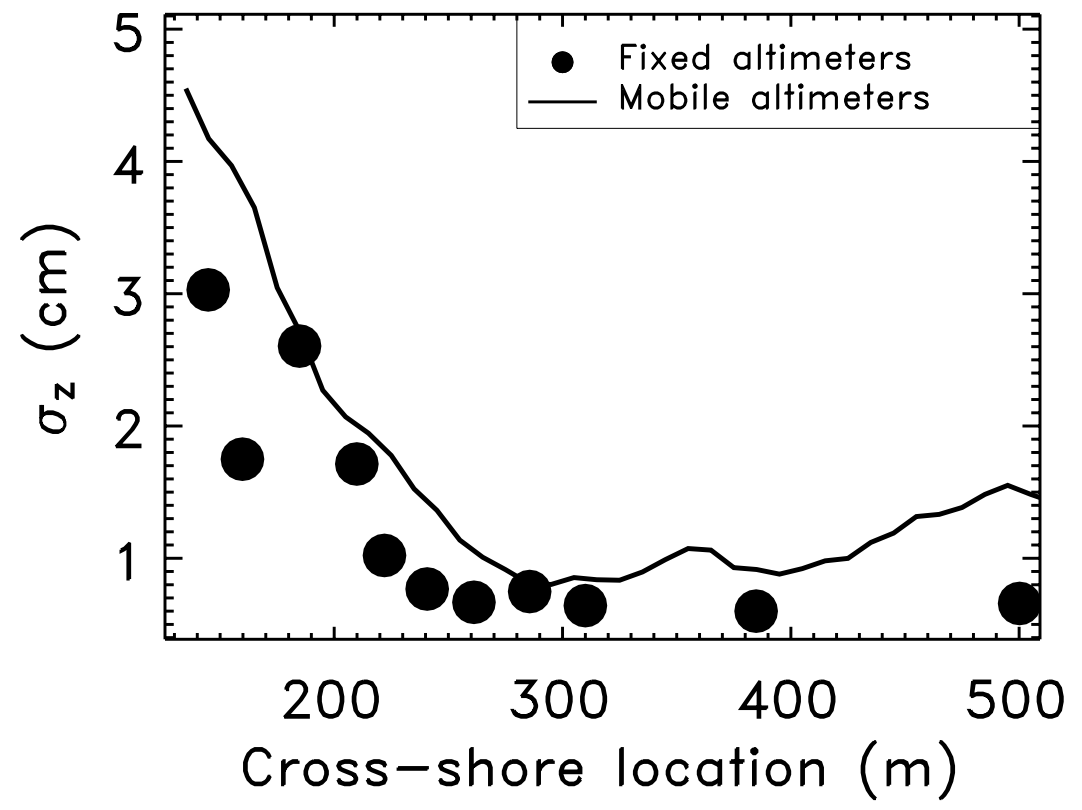

Figure 4. Temporally averaged (over 22 days) root-mean-square bedform amplitude $\sigma_{z}$ from fixed (circles) and moving (curve) altimeters versus cross-shore location. The fixed-altimeter values are from estimates centered on the times of the 22 daily surveys. 


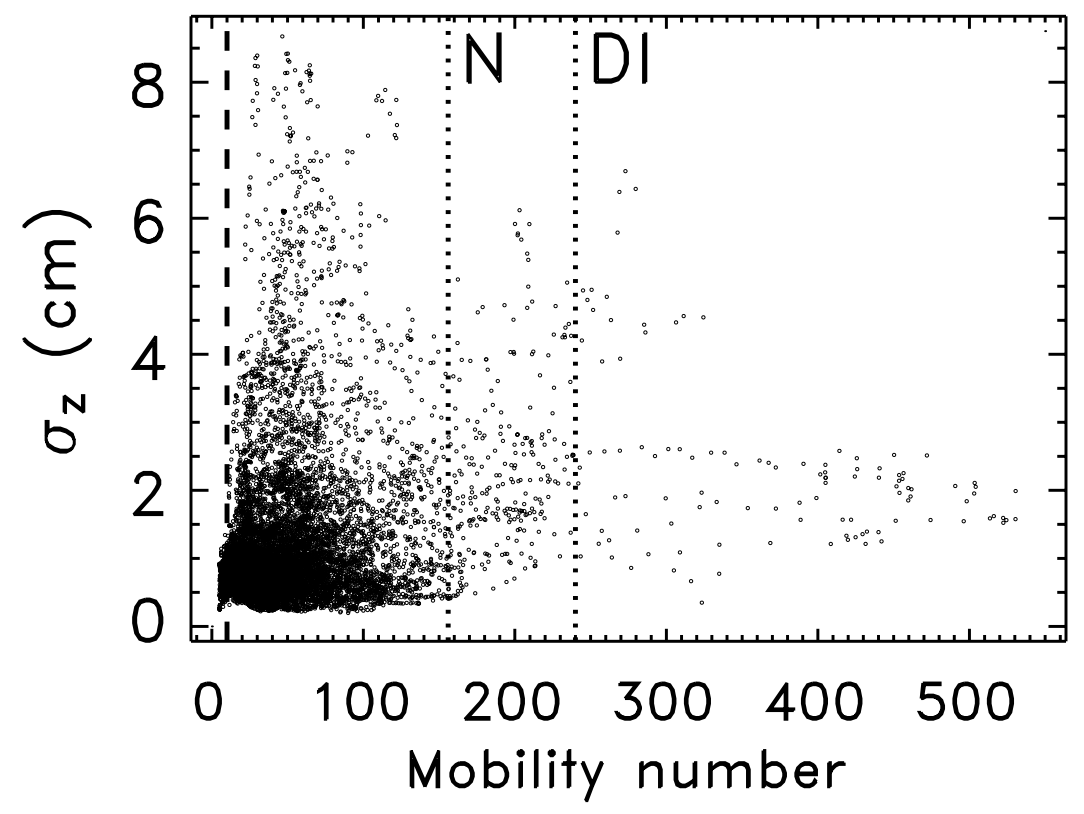

Figure 5. Root-mean-square bedform amplitude $\sigma_{z}$ versus mobility number $M$ (equation 1). Dots are estimates of $\sigma_{z}$ made with a fixed, single-point altimeter located near the current meter used to estimate the mobility number $M$. The vertical dashed line is the threshold for sediment motion $(M=10)$ for $\mathrm{D}=0.2 \mathrm{~mm}$ (Nielson 1992), and the vertical dotted lines labeled $\mathrm{N}$ and $\mathrm{DI}$ are the thresholds for transition to sheet flow from Nielson $(1992, M=156)$ and from Dingler \& Inman $(1976, M=240)$, respectively. 